\title{
Henryk Cudak
}

University of Social Sciences

\section{Behaviour Disorders of Children with the Feeling of Alienation}

\begin{abstract}
Family constitutes a social, emotional, biological, and axiological environment which is hard to be substituted by other environments. The significance of family in children's development, especially during the first development stages, is extremely high. The negative phenomenon in the family environment manifesting itself in indifference or even in only partly conscious emotional alienation, evokes the feeling of alienation in a child.
\end{abstract}

Key words: Behaviour Disorders, Family, Feeling of Alienation.

\section{Introduction}

The significance of family in children's development, especially during the first development stages, is extremely high. Family constitutes a social, emotional, biological, and axiological environment which is hard to be substituted by other environments in the form of peer, school, or local groups. On account of its natural function, family ought to provide the child with love and respect, psychological, social, and educational support, as well as satisfy his or her psychosocial needs. The aforementioned elements of the child's life in the family environment stem from the emotional bonds functioning between its members, particularly between the parents and the child, the atmosphere of the family life, the manifested parental attitudes, the upbringing and parental care styles, the interpersonal relations in social relationships inside the family, and also from the system of values accepted and executed in everyday behaviours. Properly functioning family, in which the parents are fully aware of their parental roles, uses substantial areas of the family life, in a more or less conscious manner, for the child's psychological and 
biological development, shaping his or her personality traits, social and emotional behaviours, and also satisfying needs and life aspirations.

Family as a community of members have undergone rather serious changes in the last decades - in its functioning, structure, as well as in emotional and axio-social areas. Interpersonal relations between parents and children change. Emotional bonds between family members loosens. The atomisation of social life results also in intrafamilial social and emotional alienation in the domestic environment [Cudak 2010]. The negative phenomenon in the family environment manifesting itself in indifference or even in only partly conscious emotional alienation, evokes the feeling of alienation in a child. Currently, together with progress in technicization, mass media, and the Internet, grows the number of children with emotional disorders in the form of alienation among their closest relatives - parents.

N. Sillamy [1998, p. 188], describes the feeling of alienation as a state resulting from the child's "repulsion, exclusion, and rejection by the parents, manifesting itself in hostility or mistreatment. Usually, it is displayed indirectly, as strict parenting attitudes, and excessive coldness". A similar definition, expressing the notion of alienation in the sphere of emotional disorder, is provided by M. Lopatkowa [1989, p. 4], who describes it as a "psychological state of a painful ailment characterised by a lack of bonds and constant contact with the significant other". Generally, there are the parents who are the significant others. However, attention should be paid to the fact that not only does the feeling of alienation result from and is a threat to the child's emotional sphere in the family environment, but also it indicates unfavourable or even disturbed social relations and relationships in interactions between the child and his or her parents and siblings.

Among various causes of the child's feeling of alienation, there can be enumerated the most important ones that are rooted in the family environment. Z. Tyszka [2000] primarily stresses loosening of unity ties in the family, rising social atomisation of individuals in the family environment, disintegration of the intrafamilial socialisation, diminishing authority of parents and grandparents, shift of intrafamilial roles and social positions of women. What is more, he observes increase in parent-parent and parents-children belligerence, disappearance of intrafamilial dialogue, and growth of indifference in the family life atmosphere.

The causes of the feeling of alienation are rooted also in the peer environment. As R. Pawłowska and E. Jundziłł [2000] point out, the child’s negative psychological state is conditioned by a lack of acceptance by the peer group, avoiding relations and breaking bonds with friends, and peer group criticism.

The third social environment that can evoke the feeling of alienation is a school in which the didactic function eclipses the pedagogical educational one. Teachers' and the class tutor's indifference to children's problems, the 
lack of or an incomplete diagnosis of their psychological and social needs, and their objectification, all lead to emotional and social alienation in the school environment that can negatively influence interactions in the family environment.

The causes of the child's alienation are varied, and also the emotional and social experience that accompanies this negative state is multifaceted. Mostly, as T.E. Olearczyk [2007] proves, these children are afflicted with the attitude of withdrawal, aggressive behaviours, lack of understanding by their immediate family, loss of the sense of existence, helplessness, and even despair.

The child's feeling of alienation in the family or school environment can have negative consequences in a form of educational disorders. Educational disorder is an polysemous term, frequently used by educationalists interchangeably with educational problems. Cz. Kupisiewicz and M. Kupisiewicz [2009, p. 182], describe educational disorders as "obstacles encountered in educational work with children and the youth, which manifest themselves in a form of negative, from a social and educational point of view, behaviours, which are contrary to the applicable norms and adversely affect the course and the results of the upbringing process".

The notion of educational disorders is not unambiguously understood by educationalists and psychologists. A. Lewicki claims that from the psychological and social point of view they are "certain modes of children's behaviour at variance with the goal and the direction of upbringing. Of course it is not about minor violations committed from time to time by every child, but about explicitly asocial modes of behaviour that are at the same time persistent and resistant to educational treatment".

There are various manifestations of educational disorders among children and the youth. In the classification of difficulties and educational disorders manifestations presented by educationalists and psychologists, interesting types are distinguished by T.E. Dąbrowska and B. Wojciechowska-Charlak [2005]. They list educational disorders, such as: aggression, conflicts, stubbornness, egoism, and escapes. There occur also serious personality changes, personality flaws and various non-adaptation forms. Furthermore, other behaviours of that type are: theft, taking drugs, truancy, smoking, alcohol drinking, and negative, purely asocial attitude towards individuals, social groups, and household or school duties.

Researchers of children's educational difficulties and disorders generally distinguish two groups of reasons for their negative behaviours. The first group embraces endogenous categories, which are rooted in child's innate conditioning and are related to biological factors, primarily to genetic code, brain construction, and child's negatively oriented activity. The second group of reasons for educational disorders comprises exogenous conditioning. These factors concern 
the social environment in which the child lives and functions [Lobocki 2004]. External causes concern mainly the family environment, and then, the school and peer environments (particularly, informal groups from local surroundings).

Family, as the child's closest community of members, especially, mother, father and siblings are those people who mould modes of behaviour, values, ways of conduct and interpersonal communication from the youngest age. The elements of family life which may determine the quality or educational disorders include for instance, emotional bond in the family community, atmosphere at home, parental attitudes, the frequency of parents-children dialogue, the ways of family conflicts solving, values accepted and embraced by parents, examples of parental behaviours, family's material status, general and pedagogic culture of parents.

The threats and the dysfunction of the aforesaid elements of the family life on one hand cause the state of the feeling of alienation, while on the other hand, they may contribute to behaviour disorders among children and the youth.

\section{Methodological remarks}

Contemporary times are not favourable for proper family functioning. More and more family environments are becoming threatened by the social, emotional, care, educational and axiological dysfunctions. Even a single one of the enumerated threats can induce a negative phenomenon in the form of the child's emotional isolation in the family contributing to his or her feeling of alienation in the family or even at school. The phenomenon of the child's alienation affects the growing number of adolescents. The emotional dysfunction in the child contributes to various educational disorders.

The aim of the adopted research procedure was to gain the knowledge of various educational disorders in children who had the subjective feeling of alienation in the family environment.

The object of the research became children and their parents as well as the phenomenon of social and emotional behaviours of the observed adolescents characterised by the feeling of alienation.

The research problem were formulated in the following questions: "What is the scale of the phenomenon of the feeling of alienation among the observed lower-secondary school students? Which manifestations of educational disorders appear in the lower-secondary school adolescents with the feeling of alienation?"

The fundamental method applied to the research procedure was a diagnostic survey. According to T. Pilch and T. Bauman [2002, p. 80] the method of the diagnostic survey is: "a mode of gathering knowledge of structural and functional attributes, and the dynamics of social phenomena, opinions and views of selected communities, intensification and development directions of specific phenomena 
and any other phenomena institutionally not located, having educational importance, based on a specially chosen group representing the general population where this phenomenon could be observed".

This method allows us to diagnose the phenomena of the children's feeling of alienation and their negative consequences in the form of various manifestations of educational disorders.

In the area of the applied diagnostic survey method, the research technique of a questionnaire and an unfinished sentences test was employed. The survey form was used during the research conducted among lower-secondary school students and their parents. It contained 27 questions, 18 of them were categorised, while remaining 9 were problem questions. The unfinished sentences test was constructed from 16 beginning statements which were supposed to be finished by the questioned students. It was aimed, similarly to some survey questions, to select adolescents with the feeling of alienation.

The research was led in chosen lower-secondary schools of Piotrków region in the second half of 2014. The first stage of the research procedure embraced 17 classes, videlicet 428 students. The second stage concerned 98 adolescents with the feeling of alienation and their parents (the father or the mother). 53 girls and 45 boys participated in the research.

\section{The scale of the phenomenon of the feeling of alienation among lower- secondary school students}

The problem of the alienation of children and the youth is becoming a social phenomenon. Emotional bonds are diminishing in a local environment while the atomisation of the family members lives is progressing. Each family member is concerned with his or her own problems, each has personal interests, which increases the elimination of dialogue between parents and a child and a loss of emotional-affective bond in the domestic environment. Furthermore, the phenomenon of the social atomisation between groups in local environments, also at schools and other educational institutions is spreading.

Attention should be paid to the development and the popularisation of the mass media, particularly, television and the Internet, which lead to the impoverishment of intrafamilial dialogue, emotional bonds within peer groups, social activity in the family and school life, and the local environment.

Such situations, and other ones unfavourable for the development of the emotional and social spheres in children and the youth, provoke continuous increase in their feeling of alienation.

In the research procedure, we were interested in the issue of the scale of the alienation of the lower-secondary school youth phenomenon.

The research findings concerning the state of the feeling of emotional isolation, which constituted a manifestation of the alienation among the research respondents: 
Table 1. The number of children with the feeling of alienation among the observed lower-secondary school youth

\begin{tabular}{|l|l|l|l|l|l|}
\hline \multirow{2}{*}{ No. } & \multirow{2}{*}{ Respondents' age } & \multicolumn{2}{l|}{ Respondent youth } & \multicolumn{2}{l|}{ Feeling of alienation } \\
\cline { 3 - 6 } & & No. & $\%$ & No. & $\%$ \\
\hline 1 & 14 years & 126 & 30,1 & 26 & 20,6 \\
\hline 2 & 15 years & 173 & 41,4 & 38 & 21,9 \\
\hline 3 & 16 years & 129 & 28,5 & 34 & 26,3 \\
\hline 4 & Total & 428 & 100,0 & 98 & 22,8 \\
\hline
\end{tabular}

Source: own study.

The research findings presented in the Table 1 prove that the scale of the phenomenon amongst the lower-secondary school youth is very high. As much as $22,8 \%$ of the research respondents had the feeling of alienation of various intensity. A little more than every fifth child in the first class (14 years old) demonstrated emotional disorders in his or her behaviour. As a general rule, it was restrained, which indicated the state of emotional isolation at home or school, or aversion to peer groups.

A higher percentage of the research youth at the age of $15(21,9 \%)$, though it is not a statistical difference, reveals the subjective feeling of alienation in their emotional states.

The result obtained from the research on the third class students (16 years) was unsettling. In this group more than every fourth subject $(26,3 \%)$ manifested behaviours demonstrating the internal feeling of alienation.

Generally speaking, the results presented in the Table 1 ought to be formulated into at least two conclusions:

1. The number of the lower-secondary school adolescents with the feeling of alienation rises systematically. The percentage of the researched youth $(22,8 \%)$ is an alarming signal for pedagogical educational actions in the family environment, pedagogical psychological work of the school in relation to the entire population of students, especially those who have a low-accepted social position in the students group in the class.

2. In each next lower-secondary school class there is the growing number, and therefore, the percentage, of the researched adolescents with the feeling of alienation. It is probable to be the effect of the physical, social, and emotional maturation of children. The students in the first class, despite experiencing the process of adaptation to the new school and students group of the lowersecondary school, manifest the lowest level of the feeling of alienation whereas the students in the third class, although fully school adapted, have the strongest feeling of emotional isolation. 
During the analysis and the evaluation of the scale of the feeling of alienation amongst the lower-secondary school youth, sex-related (boys and girls) determinants were pointed out.

The result of the research concerning the scale of the phenomenon of the feeling of alienation among lower-secondary schoolgirls and schoolboys are shown in the Table 2 .

Table 2. The scale of the alienation phenomenon among girls and boys from the tested lower-secondary school classes

\begin{tabular}{|l|l|l|l|l|l|}
\hline \multirow{2}{*}{ No. } & \multirow{2}{*}{ Respondents' sex } & \multicolumn{2}{l|}{ Research respondents } & \multicolumn{2}{l|}{ The feeling of alienation } \\
\cline { 3 - 6 } & & No. & $\%$ & No. & $\%$ \\
\hline 1 & Girls & 207 & 48,4 & 53 & 25,6 \\
\hline 2 & Boys & 221 & 51,6 & 45 & 20,4 \\
\hline 3 & Total & 428 & 100,0 & 98 & 22,8 \\
\hline
\end{tabular}

Source: own study.

The overall results concerning the feeling of alienation given in Table 2 prove that girls to a larger extent than boys display emotional isolation in the family and school environments. More than every fourth of the female respondents $(25,6 \%)$ showed the alienation problem. Among boys, every fifth one $(20,4 \%)$ displayed behaviours which could be assigned as symptoms of emotional disorders indicating the subjective feeling of alienation.

The obtained quantitative and qualitative results (the degree of mental isolation in the social, family, school, and peer environments) suggest certain views:

- adolescent girls are more prone to various unfavourable social and emotional situations which contribute to lower value and personal identity, which causes the feeling of alienation

- boys manifest a smaller scale of the alienation phenomenon, as they, more often than girls, compensate for the failures in the family and school life with emotional instability and social needs in peer groups.

Parents create a family environment which, on the one hand, can optimise children's social and emotional development, and their system of values, but on the other hand, it can disturb this development. Socialisation, economic, care, and educational dysfunctions in the family often cause the feeling of alienation in a child, as well as various difficulties in family, school, or peer group behaviours. Children from nearly dysfunctional families or from those with limited parental functions, grow up in conditions of narrowed interpersonal relationships. Social roles of mother and father are replaced with the mass media, especially the Internet. The child's emotional relationships are impoverished, and social relations in the family environment are weakened. Not only do the mentioned elements of the 
family system contribute to the child's alienation, but also manifest educational disorders.

The results of the research on educational disorders in children with the feeling of alienation in the family environment are presented in the Table 3.

Table 3. Types of educational disorders in family of the children with the feeling of alienation among girls and boys

\begin{tabular}{|l|l|l|l|l|l|l|l|}
\hline \multirow{2}{*}{ No. } & \multirow{2}{*}{$\begin{array}{l}\text { Type of behaviour } \\
\text { disorder }\end{array}$} & \multicolumn{2}{l}{ Girls } & \multicolumn{2}{l}{ Boys } & \multicolumn{2}{l}{ Total } \\
\cline { 3 - 8 } & & No. & $\%$ & No. & $\%$ & No. & $\%$ \\
\hline 1 & Combativeness & 11 & 20,07 & 10 & 22,2 & 21 & 21,4 \\
\hline 2 & Aggression & 13 & 24,5 & 12 & 26,7 & 25 & 25,5 \\
\hline 3 & Anger and resentment & 14 & 26,4 & 11 & 24,4 & 25 & 25,5 \\
\hline 4 & Expressing annoyance & 12 & 22,6 & 9 & 20,0 & 21 & 21,4 \\
\hline 5 & Disobedience & 16 & 30,2 & 17 & 37,8 & 33 & 33,7 \\
\hline 6 & Vulgarity & 15 & 28,3 & 14 & 31,1 & 29 & 29,6 \\
\hline 7 & Lack of disorders & 9 & 17,0 & 6 & 13,3 & 15 & 15,3 \\
\hline 8 & Total & 90 & $169,8^{*}$ & 79 & $175,5^{*}$ & 169 & $172,4^{*}$ \\
\hline
\end{tabular}

*Answers in total more than $100 \%$, as most of the respondents with the feeling of alienation indicated more than one type of behaviour disorders.

Source: own study.

The overall results presented in the Table 3 prove that 44 of the researched girls $(83 \%)$ manifest various behaviour disorders. Higher percentage of the researched boys with the feeling of alienation $(86,7 \%)$, however, indicated clear difficulties in their behaviour. There was no significant statistical difference between the tested girl and boy groups, because the results obtained with a chisquared test amounted to $x^{2}=3,86, d f=8, p . i \leq 0,05$. The tested groups did not diversify statistically the behaviour disorders between girls and boys in the home environment.

The largest part of the tested lower-secondary school youth $30,2 \%$ of girls, and $37,8 \%$ of boys) demonstrates disobedience towards parents. As the research showed, children from these families do not want to carry out their parents' requests and orders, manifest tactless behaviours or even those offending mother's or father's dignity.

A substantial part (29,6\%) of the tested adolescents with the feeling of alienation expresses vulgarity in their behaviours - more often boys $(31,1 \%)$ than girls $(28,3 \%)$. Such educational difficulties do not favour creating a warm and friendly 
home atmosphere. These children's over-emotionalism frequently vulgarises verbal behaviours towards parents or siblings in the family environment. More than every fourth respondent with the feeling of alienation displays aggressionrelated difficulties in the family. The research proves that the dominant reason for the aggressive behaviours among these children is their being witness to overemotional behaviours, also aggressive ones, in the family environment. Children's imitation of aggressive behaviours in the closest social environment results in the occurrence of such educational difficulties among adolescents. Moreover, another source of these negative behaviours is frustration resulting from unfulfilled emotional and social needs of children in the family environment.

A similar percentage of the tested youth with the feeling of alienation $(25,5 \%)$ shows educational difficulties in their behaviour in the form of anger and frequent resentment towards parents. It is a child's way to withdraw from active functioning and cooperating in the family life. On the one hand, child's anger at parents eliminates the emotional sphere between the family member, and on the other hand, it deepens the disordered social relations between the alienated child and the parents. This argument is confirmed by statements of the tested parents: "Ania is often angry at us, we have no contact with her". "Our daughter gets angry at us after every reprimand given to her, and then doesn't talk to us for a couple of days". "Mariola destroys our feelings, as she is often angry at us".

More than every fifth respondent child with the feeling of alienation $(21,4 \%)$ expresses annoyance with different emotional strength in their behaviours. This type of disorder is a bit more often displayed by girls $(22,6 \%)$ than boys $(20,0 \%)$. These behaviours are exemplified by the tested parents' statements: "There is no dialogue in our family, because our son often gets annoyed and irritated". The other typical statement of J.K.'s mother - "I feel that my daughter goes through certain emotional problems, I want to help her. Every conversation that I start annoys her, and she gets irritated by different attempted dialogues".

Excessive combativeness is the last of the analysed disordered behaviours among the adolescents with the feeling of alienation. Such negative behaviour is manifested by $21,4 \%$ of children in the family environment. Unconsciously or consciously, they provoke misunderstandings, arguments, and conflicts with their parents. This behaviour contributes to the weakening of emotional bond between the family members and the destruction of a good and friendly home atmosphere.

Together with the educational disorders displayed by the adolescents with the feeling of alienation in the family environment, there also exist negative behaviours in the school environment which vary in type and intensity.

The analysis of the results obtained from the research on behaviour disorders of the tested youth in various school situations is presented in the Table 4. 
Table 4. Educational disorders among children with the feeling of alienation in the school environment

\begin{tabular}{|l|l|l|l|l|l|l|l|}
\hline \multirow{2}{*}{ No. } & \multirow{2}{*}{$\begin{array}{l}\text { Educational } \\
\text { disorders at school }\end{array}$} & Girls & \multicolumn{2}{l}{ Boys } & \multicolumn{2}{l}{ Total } \\
\cline { 3 - 8 } & No. & $\%$ & No. & $\%$ & No. & $\%$ \\
\hline 1 & Truancy & 4 & 7,5 & 5 & 11,1 & 9 & 9,2 \\
\hline 2 & Lying & 12 & 22,6 & 11 & 24,4 & 23 & 23,5 \\
\hline 3 & $\begin{array}{l}\text { Provoking scuffles } \\
\text { and violence }\end{array}$ & 3 & 5,7 & 14 & 31,1 & 17 & 17,3 \\
\hline 4 & $\begin{array}{l}\text { Combativeness } \\
\text { and aggression }\end{array}$ & 13 & 24,5 & 16 & 35,5 & 29 & 29,6 \\
\hline 5 & $\begin{array}{l}\text { Vulgarity towards } \\
\text { teachers }\end{array}$ & 16 & 30,2 & 11 & 24,4 & 27 & 27,5 \\
\hline 6 & $\begin{array}{l}\text { Appropriate } \\
\text { behaviour }\end{array}$ & 17 & 32,1 & 9 & 20,0 & 26 & 26,5 \\
\hline 7 & Total & 65 & $122,6^{*}$ & 66 & $146,7^{*}$ & 131 & $133,7 *$ \\
\hline
\end{tabular}

*Answers in total more than $100 \%$, as most of the respondents indicated more than one type of behaviour disorders in the school environment.

Source: own study.

The analysis of the overall results presented in the Table 4 indicates that as much as $80 \%$ of the tested boys manifest different types of educational disorders in their behaviours at school. Significantly lower, but still high percentage of the tested girls $(67,4 \%)$ demonstrates various educational disorders in the school environment. Hence, there should be expressed the viewpoint that there is a significant statistical difference among the tested groups of girls and boys in the manifested educational disorders at school, as $\mathrm{x}^{2}=12,64$, $\mathrm{df}=8, \mathrm{p} . \mathrm{i} \leq 0,05$, wherein the differentiating amounts point at moderate intensity of the relation of the tested behaviour features. Statistically, boys demonstrate various educational disorders at school to a greater degree and extent in comparison to the respondent girls group.

The biggest number of educational disorders among tested boys with the feeling of alienation $(35,5 \%)$ take the form of combativeness and aggression towards school friends, teachers and other school staff. Significantly less (only $24,5 \%$ ) of such behaviours is manifested by the tested girls. This group indicates combativeness, misunderstandings, conflicts in the students' group, aggression towards school friends or even teachers and class tutors.

The unsettling state of educational disorders among the researched youth takes shape of provoking scuffles. Nearly every third respondent boy $(31,1 \%)$ causes difficulties through provoking scuffles as well as physical and psychological 
violence. Emotional isolation in a form of alienation is the negative factor for boys which causes external physical aggression, serious bullying, inflicting physical pain. These negative behaviours of the researched boys constitute some sort of compensation for their emotional deficiency.

The research results show that nearly every tenth respondent $(9,2 \%)$ displays educational disorders in a shape of truancy. A higher percentage of the tested boys $(11,1 \%)$ consciously skips classes, whereas a small part of researched girls $(7,5 \%)$ uses truancy as a way of escaping from school problems. As the research showed, the majority of the adolescents ( 7 people) who intentionally skip classes, stay at home lying to their parents about cancelled classes, or simulating illness. The two remaining people (one boy and one girl) spend time in various social environments, often educationally unfavourable ones.

\section{Final remarks}

Irregularities in the family life functioning, constant misunderstandings, conflicts, and traumatic home atmosphere disturb children's emotional and social development. Care, socialisation, and educational dysfunctions in the family environment constitutes a significant paradigm evoking the feeling of emotional isolation among children in the home environment.

Alienation of children in the home environment is becoming an increasingly common social phenomenon. There also rises the number of children and adolescents with various forms of improper behaviour, causing educational disorders in families, in the school, local, or peer environment. Weakening or elimination of emotional bonds within the family community is an unsettling situation in a contemporary family functioning. This state is deepened by the development of the mass media, particularly television and the Internet.

Therefore, various pedagogical actions ought to be undertaken at schools as well as other educational institutions in order to mould and rise pedagogical educational and socialisation awareness of parents. Parental awareness will certainly protect at least a part of the children from emotional dysfunction in the home environment, and will intentionally eliminate various behaviour disorders. Parents' pedagogical actions undertaken with children in the family community can certainly optimise appropriate functioning of the family members, including the emotional and social development of children and adolescents which will eliminate both their feeling of alienation and educational disorders at home and in other social environments.

\section{Bibliography}

Cudak H. (2010), Zagrożenia emocjonalne i społeczne džieci z rodzin rozwiedzionych, Toruń.

Dąbrowska T.E., Wojciechowska-Charlak B. (2005), Miedzy praktyka a teoriq wychowania, Lublin. 


\section{Henryk Cudak}

Kupisiewicz Cz., Kupisiewicz M. (2009), Stownik frazeologiczny, Warszawa.

Lewicki A. (2002), Psychologia kliniczna, Warszawa.

Łobocki M. (2004), Teoria wychowania w zarysie, Kraków.

Lopatkowa M. (1989), Samotnośc driecka, Warszawa.

Olearczyk T.E. (2007), Sieroctwo i osamotnienie. Pedagogiczne problemy kryzysu wspótczesnej rodziny, Kraków.

Pawłowska R., Jundziłł E. (2000), Pedagogika człłowieka samotnego, Gdańsk.

Sillamy N. (1998), Stownike psychologii, Warszawa.

Tyszka Z. (2000), Stan rodziny wspótcæesnej a wewnatrzurodzinna socjalizacja dżeci. Sytuacja w Polsce na tle krajów o wysokim poziomie rozwoju, „Rocznik Pedagogiki Rodziny”, vol. 3. 